\title{
APLICABILIDADE DA ANÁLISE DINÂMICA DO CAPITAL DE GIRO COMO INSTRUMENTO DE AVALIAÇÃO DA GESTÃO FINANCEIRA EM COOPERATIVAS AGROPECUÁRIAS*
}

\author{
Régio Marcio Toesca Gimenes ${ }^{* *}$
}

Fátima Maria Pegorini Gimenes ${ }^{* * *}$

\begin{abstract}
RESUMO O presente estudo tem como objetivo investigar a origem dos recursos que financiaram as necessidades líquidas de capital de giro de uma amostra de 64 cooperativas agropecuárias localizadas em oito estados brasileiros, no período 1999 a 2004. Os resultados obtidos permitem concluir que a demanda por capital de giro das cooperativas não foi financiada, de uma forma geral, com recursos permanentes (exigíveis a longo prazo e patrimônio líquido), havendo, assim, a necessidade de captação de recursos onerosos de curto prazo para complementar o financiamento do seu ciclo financeiro, geralmente de custo e risco mais elevados do que as demais fontes de financiamento.
\end{abstract}

Palavras-chave: cooperativismo agropecuário; financiamento do capital de giro; análise dinâmica

Código JEL: Q13

* Artigo recebido em 30 de novembro de 2006 e aprovado em 26 de fevereiro de 2008.

** Pós-doutor em Finanças pela FEA/USP, professor titular de Controladoria e Finanças da Unipar, e-mail: toesca@unipar.br

*** Doutora em Administração de Empresas, professora titular de Teoria Econômica da Unipar, e-mail: fmgimenes@unipar.br 


\title{
APPLICABILITY OF THE DYNAMIC ANALYSIS OF THE WORKING CAPITAL AS AN EVALUATION INSTRUMENT OF THE FINANCIAL ADMINISTRATION IN AGRICULTURAL COOPERATIVES
}

\begin{abstract}
This study has as purpose to investigate the origin of the funds that financed the net working capital needs of a sample of 64 located agricultural cooperatives in eight Brazilian states, in the period 1999 to 2004. The results obtained lead to the conclusion that cooperatives' demand for working capital has not been financed, in general, with permanent funds (long term liabilities and stockholders' equity). So, there is a need to raise short-term burdensome funds to complement the financing of its financial cycle, generally, with higher cost and risks than the other sources of funds.
\end{abstract}

Key words: farming cooperativism; financing of working capital; dynamic analysis 


\section{INTRODUÇÃO}

Em termos gerais, na conjuntura econômica atual, são conhecidas as dificuldades que atravessam as empresas para a formação de um capital condizente com o volume de operações que elas pretendem realizar.

O cooperativismo não foge à regra. Para financiar seu crescimento, as cooperativas agropecuárias podem financiar suas atividades com dois tipos de fontes de recursos: capitais próprios e capitais de terceiros. Por essa razão, é necessário um equilíbrio entre essas fontes, de modo que a empresa possa desenvolver suas atividades sem colocar em risco a sua autonomia financeira.

Dentre as principais questões que estão sendo debatidas atualmente no movimento cooperativista, a mais importante, conflitiva e controvertida é aquela que se relaciona ao financiamento das cooperativas agropecuárias.

Nesse sentido, este trabalho tem como objetivo identificar as fontes de financiamento das necessidades líquidas de capital de giro de uma amostra de 64 cooperativas agropecuárias, localizadas em oito estados brasileiros, no período 1999 a 2004.

\section{AS CRISES DO SISTEMA COOPERATIVISTA AGROPECUÁRIO}

Entre as décadas de 1950 e 1970 o cooperativismo agropecuário brasileiro teve forte apoio legal, técnico e financeiro do Estado, sem o qual ele não teria sido implantado. Por outro lado, ao conceder benefícios excessivos ao setor, tais como isenções fiscais e créditos subsidiados, o Estado reduziu a iniciativa de dirigentes e associados, como também distorceu os preços relativos do mercado das commodities. Dessa forma, surgiram cooperativas incapazes de sobreviver sem o amparo do Estado, assim como induziram-se dirigentes cooperativistas a aceitarem como viáveis projetos de investimento com valor presente líquido negativo, ou seja, inviáveis sob a ótica econômica (Unircoop, 2003; Schneider, 1991).

De acordo com Alves (2003, p. 29):

A tutela exercida pelo Estado tendia a se reproduzir no interior das cooperativas, que muitas vezes pareciam se comportar mais como uma entidade beneficente do que como uma organização econômica, sendo apontada pelos 
estudiosos do assunto como responsável pela fragilidade financeira crônica das cooperativas, tendo contribuído, inclusive, para a derrocada de várias empresas, como a Cooperativa Agrícola de Cotia, liquidada em 1994.

Com as alterações da política econômica brasileira a partir dos anos 1980 em virtude de uma conjuntura macroeconômica adversa, as fragilidades estruturais das cooperativas brasileiras vieram à tona, conduzindo-as a uma crise financeira sem precedentes. Boa parte da crise teve origem nas estratégias de crescimento adotadas pelas cooperativas agropecuárias durante a década anterior. O financiamento do seu processo de expansão foi realizado preferencialmente com recursos de terceiros, muitas vezes "contratados no exterior com taxas de juros internas e externas flutuantes". Com a elevação das taxas de juros e a desvalorização cambial, o encargo financeiro gerado pelo endividamento levou algumas cooperativas, em um primeiro momento, a enfrentarem graves crises de liquidez e, em alguns, casos até situações de insolvência e liquidação, já que esse tipo de sociedade não está sujeita à legislação pertinente aos processos de falência. Sobre os motivos que levaram as cooperativas a financiarem seu processo de crescimento com recursos de terceiros, Alves (2003, p. 32) afirma que "é da natureza das cooperativas, devido não apenas à legislação pertinente, mas, também, à própria doutrina cooperativista, a existência de sérios limites à autocapitalização".

Quando a própria Lei do Cooperativismo determina que 15\% das sobras devem ser retidas pela empresa, sendo 10\% destinados ao Fundo de Reserva e 5\% ao Fundo de Assistência Técnica, Educacional e Social (Fates), está implícita a limitação ao autofinanciamento. Da mesma forma, a capitalização da cooperativa pela subscrição de novas quotas-partes por parte dos associados parece pouco factível, uma vez que o acesso aos bens e serviços prestados pela cooperativa, assim como as sobras, é independente do número de quotas-partes detidas por cada associado (Alves, 2003).

Benetti (1985, p. 273) identifica outro motivo para o uso intensivo de recursos de terceiros no financiamento do processo de crescimento das cooperativas agropecuárias. Segundo o autor, o caráter descontinuado do crescimento da produção de soja exigiu, a partir de 1971, um grande aporte de recursos para investimentos em capacidade de estocagem e transporte, $\mathrm{e}$ "muitos desses investimentos, como os relativos à estocagem e à construção de terminais, não devem ter obedecido a critérios de rentabilidade, conside- 
rados em si mesmos". Eles teriam sido realizados simplesmente com o objetivo de operacionalizar a atividade de comercialização de grãos. O resultado foi um aumento expressivo das contas patrimoniais dessas cooperativas, apresentando, de um lado, um ativo imobilizado constituído por capital de baixa rentabilidade, e, de outro, um passivo oneroso representado pelo endividamento.

Um outro aspecto a destacar é que as cooperativas de pequeno porte, antes do boom da soja, não tinham capacidade de gerar excedentes compatíveis com o volume de investimentos almejados. "Além disso, a maioria dos cooperados era formada por pequenos produtores, incapazes, portanto, de transferir recursos para as cooperativas.” Dentre outros fatores que contribuíram para acentuar a crise nas cooperativas agropecuárias destaca-se a falácia do princípio cooperativista do controle democrático. Na realidade, ele é muito pouco exercido, os dirigentes normalmente manipulam as assembléias gerais, aprovando projetos do seu interesse, ficando totalmente alheios ao controle do corpo social. Com isso, ficou mais fácil ocorrerem "gestões temerárias e irregulares, cometidas por administradores incompetentes e/ou corruptos" (Alves, 2003, p. 34).

$\mathrm{Na}$ década de 1990 as cooperativas agropecuárias passaram a atuar como bancos, fornecendo recursos para os produtores rurais que não conseguiam captá-los no mercado financeiro. Alerta-se para o fato de que as cooperativas passam, a partir de então, a assumir riscos crescentes, uma vez que antecipavam os recursos aos cooperados e sua dívida era convertida em equivalentes de produto. Como as cooperativas não possuíam recursos próprios para realizar esses empréstimos aos produtores, elas o faziam recorrendo às instituições financeiras, e, portanto, acabavam assumindo o risco do crédito. Na época da colheita, em havendo frustração de safra, o produtor não honrava suas obrigações para com a cooperativa, e esta obrigava-se a renegociar suas dívidas com os agentes financeiros a taxas de juros cada vez mais altas (Gonzales; Costa, 1998).

A abertura comercial e a acirrada competição com os produtos importados, muitas vezes subsidiados nos países de origem, fizeram com que as cooperativas enfrentassem dificuldades para garantir o suprimento das matérias-primas necessárias à manutenção das suas plantas industriais. Pode-se dar como exemplo o ocorrido no setor de produtos lácteos, em que a con- 
corrência tornou-se mais acirrada a partir da entrada de grandes empresas multinacionais no mercado interno, com destaque para a italiana Parmalat. A competição que anteriormente se dava no mercado de produtos passa a ocorrer, também, na seleção e fidelização dos produtores rurais. Apesar da situação crítica pela qual passava a agricultura, após a implantação do Plano Real, só no final de 1995 o governo propôs a negociação das dívidas agrícolas por meio da Lei ${ }^{\circ}$ 9.138. Para que os agentes financeiros aceitassem participar das negociações, as dívidas "seriam securitizadas, sendo respaldadas por títulos públicos federais, o que significa que o governo assumiria o risco de crédito do agente financeiro" (Alves, 2003).

No caso específico das cooperativas agropecuárias, foi criado o Programa de Revitalização das Cooperativas de Produção Agropecuária (Recoop). O Recoop foi instituído pela Medida Provisória no 1.715/1998, tendo como objetivo reestruturar e capitalizar as cooperativas de produção agropecuária visando ao seu desenvolvimento auto-sustentado. O Tesouro Nacional alocaria ao programa recursos da ordem de $\mathrm{R} \$ 2,1$ bilhões, gerados através da emissão de títulos públicos, e os prazos de amortização poderiam ser estabelecidos em até 15 anos com encargos financeiros calculados à razão de 4\% ao ano mais a variação do IGP-DI para as modalidades: (a) dívidas junto ao sistema financeiro; (b) dívidas com cooperados; (c) dívidas tributárias; (d) investimentos e capital de giro associado (Bianco; Cardoso; Fuchida; Freitas, 1998).

De acordo com Ew (2001, p. 54-55), para se beneficiar das medidas do programa a cooperativa deveria solicitar o seu enquadramento através de uma carta-consulta e, se aceita, apresentar um Plano de Desenvolvimento Cooperativo (PDC), previamente aprovado pela maioria dos seus associados em assembléia geral, ao Comitê Executivo do Recoop, contemplando os cinco projetos do programa, quais sejam:

(1) Projeto de Reestruturação e Viabilidade Econômico-financeira: procura redirecionar as atividades da cooperativa para seu foco principal.

(2) Projeto de Capitalização: propõe recursos novos para a reestruturação da cooperativa.

(3) Projeto de Profissionalização da Gestão: busca uma estrutura profissional para a cooperativa adequada ao mercado competitivo. 
(4) Projeto de Organização e Profissionalização dos Associados: objetiva fidelizar os associados à cooperativa.

(5) Projeto de Monitoramento do PDC: acompanha a execução dos demais projetos.

Em 2001, estabeleceu-se um teto de 9,5\% a.a. para a variação do IGP-DI nos contratos realizados no âmbito do Recoop. A partir de 2002, os encargos financeiros incidentes sobre as operações do programa foram novamente alterados, com a determinação de uma taxa de juros fixa em 9,75\% a.a. O comitê executivo do programa analisou 651 cartas-consulta entregues pelas cooperativas interessadas no programa. Destas, 439 foram consideradas habilitadas a passar para a etapa seguinte, na qual deveria ser elaborado o Plano de Desenvolvimento Cooperativo (PDC). Ao final dessa fase, 322 planos foram aprovados pelo comitê executivo (Alves, 2003).

Segundo reportagem da revista A Granja, apenas 132 cooperativas conseguiram firmar contratos no âmbito do Recoop, envolvendo recursos da ordem de $\mathrm{R} \$ 796$ milhões, o que perfaz apenas 37,9\% dos recursos disponibilizados originalmente pelo programa. Já a revista Agroanalysis afirma, em reportagem sobre o Recoop, que, das 125 operações contratadas no âmbito do Recoop até 19 de janeiro de 2001, 95 haviam sido realizadas pelo Banco do Brasil, 16 pelo BRDE e apenas 14 pelo restante das instituições financeiras.

\section{RESULTADOS DE INVESTIGAÇõES EMPÍRICAS SOBRE O EQUILÍBRIO ECONÔMICO-FINANCEIRO DE COOPERATIVAS AGROPECUÁRIAS}

Apresentam-se neste tópico os resultados de algumas investigações empíricas sobre a situação econômico-financeira de cooperativas agropecuárias, cujas análises foram elaboradas através do cálculo de indicadores extraídos dos seus demonstrativos financeiros.

Gimenes (1999), utilizando uma amostra de 42 cooperativas agropecuárias singulares do Estado do Paraná, ou seja, $81 \%$ do universo a ser pesquisado, realizou uma avaliação dos seus demonstrativos contábeis, através de uma seleção de índices econômico-financeiros.

Além do cálculo dos índices, o autor criou os denominados "índicespadrão", cujos resultados apurados para a mediana foram agrupados na tabela 1. Segundo o autor, a situação econômico-financeira das cooperativas 
Tabela 1: Índices econômico-financeiros de uma amostra de cooperativas agropecuárias do Estado do Paraná

\begin{tabular}{|c|c|c|c|}
\hline Índice & Fórmula & Un. & Mediana \\
\hline ESTRUTURA DOS ATIVOS & - & - & - \\
\hline Aplicações no circulante & AC/AT & $\%$ & 49,50 \\
\hline Aplicações no realizável & RLP/AT & $\%$ & 7,50 \\
\hline Aplicações no permanente & AP/AT & $\%$ & 34,50 \\
\hline ENDIVIDAMENTO & - & - & - \\
\hline Endividamento de curto prazo & $\mathrm{PC} / \mathrm{CT}$ & $\%$ & 72,50 \\
\hline Endividamento de longo prazo & ELP/CT & $\%$ & 27,50 \\
\hline Dependência bancária & EMP/CT & $\%$ & 58,34 \\
\hline Índice de cobertura de juros & SO/DF & $\$$ & 0,16 \\
\hline Endividamento geral & $\mathrm{PL} / \mathrm{CT}$ & $\%$ & 121,12 \\
\hline Alavancagem financeira & SOL/SL & - & 0,51 \\
\hline AUTOFINANCIAMENTO & - & - & - \\
\hline Imobilização do patrimônio líquido & $\mathrm{AP} / \mathrm{PL}$ & $\%$ & 94,00 \\
\hline Participação do capital social & $\mathrm{CS} / \mathrm{PL}$ & $\%$ & 39,28 \\
\hline Participação das reservas & $\mathrm{RE} / \mathrm{PL}$ & $\%$ & 63,31 \\
\hline Participação das sobras acumuladas & SA/PL & $\%$ & 0,27 \\
\hline CAPACIDADE DE PAGAMENTO & - & - & - \\
\hline Liquidez corrente & $\mathrm{AC} / \mathrm{PC}$ & $\$$ & 1,12 \\
\hline Liquidez seca & $(\mathrm{AC}-\mathrm{ES}) / \mathrm{PC}$ & $\$$ & 0,79 \\
\hline Liquidez geral & $(\mathrm{AC}+\mathrm{RLP}) /(\mathrm{PC}+\mathrm{ELP})$ & $\$$ & 1,03 \\
\hline Capital circulante líquido & CCLAC & $\%$ & 11,22 \\
\hline Participação dos valores a receber & VR/AC & $\%$ & 55,79 \\
\hline CICLO DE ATIVIDADES & - & - & - \\
\hline Prazo médio de estocagem & $(E M / C) * 360$ & Dias & 28 \\
\hline Prazo médio de recebimento & $(\mathrm{RM} / \mathrm{ROB}) * 360$ & Dias & 52 \\
\hline Prazo médio de pagamento & $(\mathrm{FM} / \mathrm{C}) \star 360$ & Dias & 31 \\
\hline Ciclo operacional & $\mathrm{PME}+\mathrm{PMR}$ & Dias & 80 \\
\hline Ciclo financeiro & PME+PMR-PMP & Dias & 49 \\
\hline RENTABILIDADE & - & - & - \\
\hline Giro dos ativos & ROL/AT & $x$ & 1,61 \\
\hline Margem operacional própria & SOP/ROL & $\%$ & 0,64 \\
\hline Margem líquida & SL/ROL & $\%$ & 0,31 \\
\hline Retorno sobre o ativo & SL/AT & $\%$ & 5,01 \\
\hline Retorno dos associados & SL/PL & $\%$ & 1,23 \\
\hline
\end{tabular}

Fonte: Adaptado de Gimenes (1999). 
selecionadas pela amostra, pelo menos na mediana, não refletia uma situação de equilíbrio financeiro, o que facilmente ficou evidenciado pelos resultados da análise apresentados a seguir:

(a) A liquidez geral das cooperativas era apertada, e pressionando essa liquidez encontrava-se a conta valores a receber, que representou em algumas cooperativas $72,27 \%$ dos ativos circulantes. A expressiva participação da conta valores a receber nos ativos circulantes ocorria pela ausência do governo federal nas atividades de financiamento do ciclo operacional dos produtores rurais. As cooperativas, diante dessa realidade, acabavam financiando a atividade produtiva dos seus cooperados, assumindo todo o risco da inadimplência.

(b) O grau de endividamento das cooperativas revelou uma predominância de recursos de terceiros em relação aos recursos próprios. Quanto à composição desse endividamento, constatou-se que $72,50 \%$ desses recursos eram obrigações de curto prazo. Agravando essa situação, verificou-se que, na mediana, a sobra operacional cobria apenas $16 \%$ dos encargos financeiros gerados pelo endividamento das cooperativas. Esses valores revelavam, a princípio, um alto grau de dependência de recursos de terceiros, principalmente de curto prazo, e isto implicava assumir maiores níveis de risco financeiro.

(c) Com relação à imobilização do patrimônio líquido, constatou-se em $50 \%$ das cooperativas um índice igual a $94 \%$, ou seja, praticamente a totalidade dos recursos próprios (patrimônio líquido) era utilizada para financiar as aplicações em ativos fixos, restando apenas $6 \%$ desse recurso (capital circulante próprio) para financiar as necessidades de capital de giro.

(d) As reservas equivaliam a 63,31\% do patrimônio líquido das cooperativas, o que demonstrava a preferência dos gestores em alocar as sobras para esses fundos, que, por serem indivisíveis, não pertenciam aos cooperados. A justificativa utilizada pelos gestores para essa decisão estava fundamentada no argumento de que fundos indivisíveis são estáveis, diminuindo, portanto, a probabilidade de crises de liquidez.

(e) Em $80 \%$ das cooperativas agropecuárias paranaenses a participação das sobras acumuladas no patrimônio líquido foi inferior a 2,16\%. 
Esse dado demonstrava a baixa capacidade de autofinanciamento das cooperativas, que podia ser explicada pelas reduzidas margens operacionais resultantes de suas atividades, bem como pela conjuntura econômica nacional amplamente desfavorável às atividades do setor agrícola.

(f) A margem bruta das cooperativas apresentava, na mediana, um valor equivalente a $11,31 \%$ da receita operacional líquida. Encargos sobre salários, processos tecnológicos ultrapassados e equipamentos obsoletos eram os responsáveis pela redução dessa margem. Já a margem operacional situou-se em $0,64 \%$, e para 70\% das cooperativas o índice estava abaixo de 1,01\%. Quanto à margem líquida, a mediana apresentou um valor igual a $0,31 \%$, e para $30 \%$ das cooperativas o valor foi negativo, sendo inferior a $1,87 \%$ para $80 \%$.

(g) O retorno sobre o patrimônio líquido, que identifica a taxa de recuperação do capital dos cooperados, apresentou, na mediana, um valor igual a $1,23 \%$, e para $30 \%$ das cooperativas o índice foi negativo, estando abaixo de $2,96 \%$ ao ano para $70 \%$.

Bastiani (2001) também realizou uma investigação empírica sobre a estrutura e custo de capital de 14 cooperativas agropecuárias singulares localizadas no estado do Paraná no período 1995 a 1999. As principais conclusões da pesquisa são apresentadas a seguir:

(a) As cooperativas selecionadas pela amostra tinham uma maior dependência do crédito de curto prazo, representado pela crescente participação do passivo circulante na estrutura financeira das sociedades. Os recursos de terceiros a longo prazo contribuíam com uma proporção média de $15 \%$ das fontes totais de recursos, e a participação dos recursos próprios declinava, gradativamente, de uma participação média de 53\% em 1995 para 35\% em 1999;

(b) Os resultados obtidos quanto à participação de capital próprio evidenciavam que, quando existiam boas oportunidades de crescimento, as cooperativas davam preferência ao capital próprio. Por outro lado, quando o crescimento era baixo, constatava-se a predominância de capital de terceiros;

(c) Com relação ao custo médio dos recursos de terceiros, apurou-se uma taxa de $13 \%$ ao ano para o caso dos empréstimos a taxas fixas e 
9\% ao ano mais variação cambial nos casos de empréstimos contratados em moeda estrangeira.

(d) As dificuldades encontradas pelas cooperativas para captarem recursos de seus associados foram: descapitalização dos seus associados, falta de consciência dos associados em relação ao financiamento da cooperativa, redução do preço do produto entregue pelo associado, taxas de juros inferiores às obtidas no mercado financeiro e falta de liquidez das quotas-parte.

(e) Todas as cooperativas analisadas realizavam operações com terceiros (não associados) com o objetivo de reduzir eventual ociosidade de suas instalações e intensificar a capitalização, uma vez que o resultado destas operações não era distribuído aos associados, ficando retido nos fundos indivisíveis à disposição dos gestores.

(f) A maior parte das cooperativas (64\%) afirmava que seu volume de recursos disponíveis não era suficiente para atender à demanda por novos projetos de investimento. Alguns dirigentes (36\%) informaram que sacrificariam o capital de giro para realizar tais inversões.

Para finalizar, Bastiani (2001, p. 24-25) afirma que:

(...) as cooperativas agropecuárias não têm o mesmo leque de alternativas que se apresenta às sociedades mercantis nas decisões sobre as respectivas estruturas de capital, principalmente por não poderem emitir títulos que permitam o levantamento de recursos a longo prazo no mercado de capitais. Quanto às formas de capitalização, via sobras líquidas geradas, estas são limitadas e, na maioria das vezes, com finalidades definidas e estão sujeitas às flutuações decorrentes dos resultados líquidos obtidos pela entidade cooperativa os quais são altamente influenciados pelo risco de produção e de preços da agropecuária. A capitalização, através de novas chamadas de capital, também padece de sérias restrições de natureza interna e externa à cooperativa e onde os conflitos de agência se manifestam.

Alves (2003), em sua investigação empírica, procurou analisar a situação econômico-financeira do cooperativismo agropecuário tanto em termos absolutos como comparativamente à situação das cooperativas mutuárias do BRDE - Banco Regional de Desenvolvimento do Extremo Sul.

Dentre os principais resultados da pesquisa destacam-se os seguintes: 
(a) As 50 maiores cooperativas brasileiras apresentavam grau de endividamento elevado e com tendência de crescimento nos últimos anos.

(b) O grau de endividamento das cooperativas tendia a ser estruturalmente mais elevado do que o de firmas industriais, em virtude dos repasses de crédito efetuados por aquelas empresas a seus associados.

(c) As cooperativas beneficiadas pelo Recoop apresentavam nível de endividamento substancialmente mais elevado do que o do conjunto das demais cooperativas.

(d) Existia alta concentração dos empréstimos do BRDE em cooperativas com frágil equilíbrio financeiro. A capacidade de pagamento das cooperativas financiadas pelo BRDE apresentava índices inferiores aos demonstrados pelas cooperativas agropecuárias paranaenses.

Alves (2003; p. 84) conclui sua investigação com as seguintes palavras:

Sob a hipótese de que as grandes empresas transnacionais possuem um leque de opções mais amplo no que se refere ao crédito de longo prazo, uma vez que podem recorrer com maior facilidade aos mercados financeiro e de capitais internacionais e às transações intracompanhia, as empresas controladas por residentes, entre as quais se incluem as cooperativas, revelam-se como as principais demandantes potenciais de crédito de longo prazo junto ao SFN. Entretanto, percebe-se uma certa resistência dos agentes do SFN no que se refere à concessão de crédito às cooperativas agropecuárias, o que ficou evidenciado pelo reduzido valor alcançado pelas operações contratadas no âmbito do Recoop.

\section{PESQUISA DOCUMENTAL SOBRE O FINANCIAMENTO DAS NECESSIDADES LÍQUIDAS DE CAPITAL DE GIRO EM COOPERATIVAS AGROPECUÁRIAS}

Diante da revisão da literatura e do resultado das investigações empíricas apresentadas no item anterior, o objetivo desta pesquisa documental é avaliar, em um número maior de cooperativas, localizadas em diferentes estados da federação brasileira, em um período mais longo (1999 a 2004), como as cooperativas agropecuárias selecionadas por uma amostra não probabilística financiaram o seu processo de expansão, especificamente quanto às necessidades líquidas de capital de giro. 


\subsection{Modelo dinâmico de análise financeira do capital de giro}

Para utilizar o modelo dinâmico de análise financeira do capital de giro é necessário reclassificar as contas patrimoniais em circulantes e não circulantes, bem como subdvidir o grupo das contas circulantes em operacionais e financeiras (Pereira, 1993; Matarazzo, 1998; Santos, 2005). A partir da reclassificação das contas patrimoniais, o modelo utiliza os seguintes indicadores:

\subsubsection{Necessidade líquida de capital de giro - NLCDG}

O valor da NLCDG revela o montante necessário de recursos para manter o giro dos negócios (Santi Filho; Olinquevitch, 1995, e Marques; Braga, 1995).

A NLCDG pode ser mensurada pela seguinte fórmula (1):

$\mathrm{NLCDG}=\mathrm{ACO}-\mathrm{PCO}$

Sendo:

NLCDG - Necessidade Líquida de Capital de Giro (R\$)

ACO - Ativo Circulante Operacional (R\$)

PCO - Passivo Circulante Operacional (R\$)

\subsubsection{Tesouraria - T}

Essa variável identifica o grau de utilização de recursos de terceiros de curto prazo para financiar as necessidades líquidas de capital de giro da organização. A variável T - Tesouraria pode ser calculada pela fórmula (2):

$$
\mathrm{T}=\mathrm{ACF}-\mathrm{PCF}
$$

Sendo:

$\mathrm{T}$ - Tesouraria $(\mathrm{R} \$)$

ACF - Ativo Circulante Financeiro (R\$)

PCF - Passivo Circulante Financeiro (R\$)

\subsubsection{Longo prazo - LP}

Essa variável relaciona a conta exigível de longo prazo, cuja presença na estrutura financeira da empresa revela a existência de fontes de recursos não exigíveis no próximo período anual, e a conta realizável de longo prazo, que 
representa os investimentos de lenta recuperação do capital (Santi Filho; Olinquevitch, 1995). A variável LP é mensurada pela fórmula (3):

$$
\mathrm{LP}=\mathrm{ELP}-\mathrm{RLP}
$$

Sendo:

$$
\begin{aligned}
& \text { LP } \quad \text { Longo Prazo (R\$) } \\
& \text { ELP - Exigível de Longo Prazo (R\$) } \\
& \text { RLP - Realizável de Longo Prazo (R\$) }
\end{aligned}
$$

\subsubsection{Capital de giro próprio - CDGP}

Essa variável determina o volume de recursos próprios (patrimônio líquido) disponível para realizar as aplicações nos ativos da organização. A fórmula (4) descreve o cálculo do capital de giro próprio:

$$
\mathrm{CDGP}=\mathrm{PL}-\mathrm{AP}
$$

Sendo:

CDG - Capital de Giro Próprio (R\$)

PL - Patrimônio Líquido (R\$)

AP - Ativo Permanente (R\$)

\subsubsection{Termômetro da situação financeira - TSF}

A participação dos recursos de terceiros de curto prazo no financiamento das necessidades líquidas de capital de giro da empresa pode ser mensurada pelo índice TSF. A partir do índice, podem-se avaliar a magnitude da tesouraria negativa em relação às necessidades líquidas de capital de giro e, principalmente, sua tendência ao longo do tempo, uma vez que a persistência desse tipo de financiamento pode conduzir a uma situação de completo desequilíbrio financeiro (Fleuriet; Kehdy; Blanc, 1980; Santi Filho; Olinquevitch, 1995).

O Termômetro da Situação Financeira (SF) pode ser calculado pela fórmula (5):

$$
\mathrm{TSF}=\frac{\mathrm{T}}{\mathrm{NLCDG}}
$$

Sendo: 
TSF - Termômetro da Situação Financeira (R\$)

$\mathrm{T}$ - Tesouraria $(\mathrm{R} \$)$

NLCDG - Necessidade Líquida de Capital de Giro (R\$)

Quando o saldo de tesouraria se torna negativo e assume tendência crescente, produzindo um hiato entre as curvas da NLCDG - Necessidade Líquida de Capital de Giro - e do CDGP - Capital de Giro Próprio, diz-se que a empresa está em efeito tesoura (Silva, 1995).

\subsection{Procedimentos metodológicos}

A pesquisa é de natureza descritiva e documental, e a amostra selecionada é composta de 64 cooperativas agropecuárias, cuja distribuição geográfica descreve-se na tabela 2.

A partir dos demonstrativos financeiros publicados nos relatórios da diretoria das cooperativas agropecuárias para o período 1999 a 2004, a análise foi desenvolvida com as seguintes etapas:

(a) Padronização dos demonstrativos financeiros;

(b) Correção dos seus valores nominais;

(c) Reclassificação das contas patrimoniais;

(d) Cálculo dos índices financeiros;

(e) Análise e discussão dos resultados.

Tabela 2: Distribuição geográfica das cooperativas agropecuárias

\begin{tabular}{lcc}
\hline $\begin{array}{l}\text { Localização } \\
\text { (Estado) }\end{array}$ & $\begin{array}{c}\text { Número de cooperativas } \\
\text { pesquisadas }\end{array}$ & Participação na amostra (\%) \\
\hline Paraná & 31 & 48,44 \\
\hline Minas Gerais & 10 & 15,63 \\
\hline Santa Catarina & 12 & 18,75 \\
\hline São Paulo & 3 & 4,69 \\
\hline Rio Grande do Sul & 2 & 3,13 \\
\hline Mato Grosso & 3 & 4,69 \\
\hline Mato Grosso do Sul & 2 & 3,13 \\
\hline Goiás & 1 & 1,54 \\
\hline Total & 64 & 100,00
\end{tabular}

Fonte: Resultados da pesquisa. 
As limitações da pesquisa foram concentradas nas dificuldades de obtenção dos demonstrativos financeiros das sociedades cooperativas, principalmente daquelas que emitiam sinais aparentes de insolvência.

\subsection{Resultados da pesquisa para o período 1999 a 2004}

No quadro 1 apresentam-se os valores dos índices NLCDG, T, LP e CDGP para o período em estudo.

Analisando-se os resultados apresentados no quadro 1, percebe-se que:

Em 1999, 52 cooperativas, ou 81,25\% da amostra, apresentaram valores positivos para a NLCDG, e em 12 cooperativas, ou seja, 18,75\% da amostra, o índice apresentou um valor negativo. Ao longo do período analisado observam-se um aumento do número de cooperativas com valores positivos para a NLCDG (96,88\% em 2004) e, ao mesmo tempo, uma redução do número de cooperativas com valores negativos para a NLCDG $(3,13 \% \mathrm{em}$ 2004). A figura 1 ilustra a tendência da variável NLCDG no período 1999 a 2004.

No exercício de 1999, 13 cooperativas, ou seja, 20,31\% da amostra, apresentaram um valor positivo para o índice Tesouraria-T, caracterizando uma situação de folga financeira. Esse número de cooperativas reduziu-se ao longo do período, quando, em 2004, apenas seis cooperativas, ou 9,38\% da amostra, apresentaram tal condição. Por outro lado, aumentou o número de cooperativas que financiaram seu capital de giro com recursos de terceiros de curto prazo (90,63\% em 2004). A figura 2 ilustra a tendência do índice Tesouraria-T no período 1999 a 2004.

Quadro 1: Financiamento das necessidades líquidas de capital de giro das cooperativas agropecuárias pesquisadas no período 1999 a 2004

\begin{tabular}{|c|c|c|c|c|c|c|c|c|c|c|c|c|}
\hline \multirow[t]{2}{*}{ Variáveis } & \multicolumn{2}{|c|}{1999} & \multicolumn{2}{|c|}{2000} & \multicolumn{2}{|c|}{2001} & \multicolumn{2}{|c|}{2002} & \multicolumn{2}{|c|}{2003} & \multicolumn{2}{|r|}{2004} \\
\hline & $\mathrm{N}^{\circ}$ & $\%$ & $\mathrm{~N}^{\circ}$ & $\%$ & $\mathrm{~N}^{\circ}$ & $\%$ & $\mathrm{~N}^{\circ}$ & $\%$ & $\mathrm{~N}^{\circ}$ & $\%$ & $\mathrm{~N}$ & ○ $\%$ \\
\hline $\operatorname{NLCDG}(+)$ & 52 & $81,25 \%$ & 54 & $84,38 \%$ & 56 & $87,50 \%$ & 59 & $92,19 \%$ & 60 & $93,75 \%$ & 62 & $96,88 \%$ \\
\hline NLCDG (-) & 12 & $18,75 \%$ & 10 & $15,63 \%$ & 8 & $12,50 \%$ & 5 & $7,81 \%$ & 4 & $6,25 \%$ & 2 & $3,13 \%$ \\
\hline $\mathrm{T}(+)$ & 13 & $20,31 \%$ & 12 & $18,75 \%$ & 11 & $17,19 \%$ & 9 & $14,06 \%$ & 8 & $12,50 \%$ & 6 & $9,38 \%$ \\
\hline $\mathrm{T}(-)$ & 51 & $79,69 \%$ & 52 & $81,25 \%$ & 53 & $82,81 \%$ & 55 & $85,94 \%$ & 56 & $87,50 \%$ & 58 & $90,63 \%$ \\
\hline $\mathrm{LP}(+)$ & 60 & $93,75 \%$ & 57 & $89,06 \%$ & 53 & $82,81 \%$ & 52 & $81,25 \%$ & 50 & $78,13 \%$ & 47 & $73,44 \%$ \\
\hline $\mathrm{LP}(-)$ & 4 & $6,25 \%$ & 7 & $10,94 \%$ & 11 & $17,19 \%$ & 12 & $18,75 \%$ & 14 & $21,88 \%$ & 17 & $26,56 \%$ \\
\hline $\operatorname{CDGP}(+)$ & 49 & $76,56 \%$ & 45 & $70,31 \%$ & 44 & $68,75 \%$ & 42 & $65,63 \%$ & 41 & $64,06 \%$ & 39 & $60,94 \%$ \\
\hline $\operatorname{CDGP}(-)$ & 15 & $23,44 \%$ & 19 & $29,69 \%$ & 20 & $31,25 \%$ & 22 & $34,38 \%$ & 23 & $35,94 \%$ & 25 & $39,06 \%$ \\
\hline
\end{tabular}


Figura 1: NLCDG das cooperativas agropecuárias pesquisadas no período 1999 a 2004

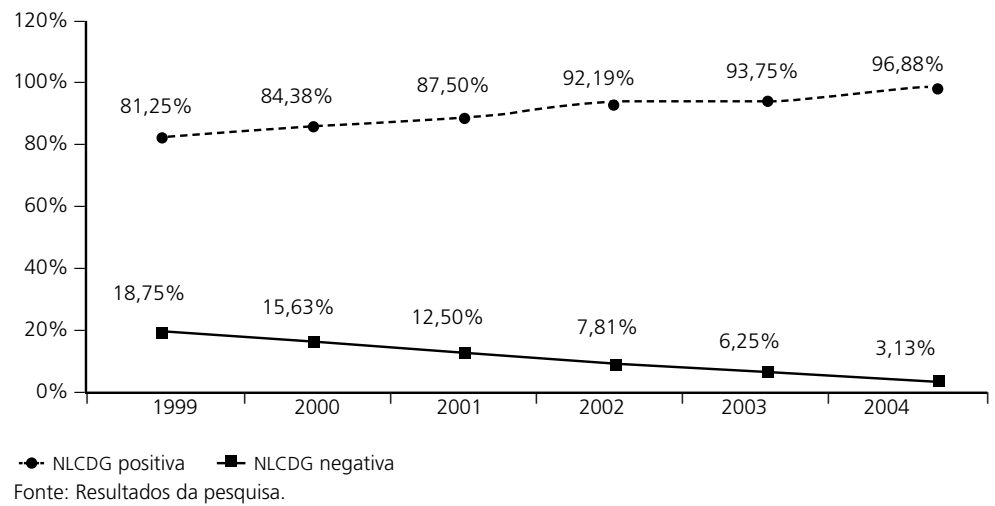

Figura 2: Tesouraria das cooperativas agropecuárias no período 1999 a 2004

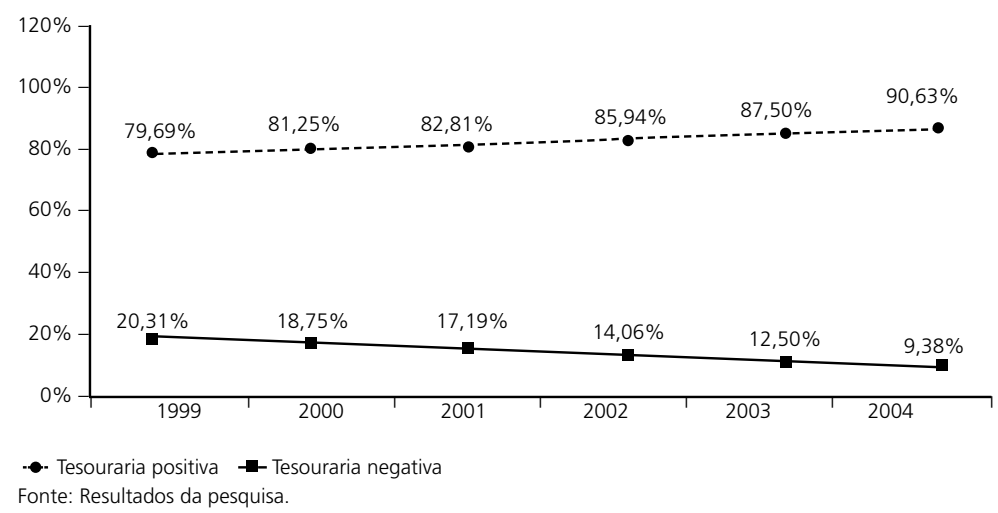

Em 60 cooperativas, ou seja, 93,75\% da amostra, o índice LP apresentou um valor positivo em 1999. No decorrer do período verifica-se uma redução das fontes de financiamento de longo prazo e um aumento das aplicações de longo prazo (26,56\% em 2004).

A figura 3 ilustra a tendência da variável LP - Longo Prazo no período 1999 a 2004.

Em 1999, 76,56\% das cooperativas geraram capital de giro próprio (autofinanciamento) e 23,44\%, ou 15 cooperativas, apresentaram valores negativos para o CDGP - Capital de Giro Próprio. Observando-se os valores do CDGP no decorrer do período, identifica-se uma redução do número de cooperativas capazes de gerar capital próprio para financiar o giro das suas 
atividades (60,94\% em 2004). A figura 4 ilustra a tendência da variável CDGP - Capital de Giro Próprio no período 1999 a 2004.

Analisando-se os valores calculados dos índices do último ano em estudo, 2004, verifica-se que:

Em 62 cooperativas, ou seja, 96,88\% da amostra, o índice NLCDG apresentou valor positivo, isto é, as aplicações de capital de giro foram superiores às fontes de capital de giro, portanto a maior parte das cooperativas analisadas não conseguiu financiar suas atividades operacionais exclusivamente com recursos do passivo operacional ou cíclico. Em duas cooperativas, ou seja, 3,13\% da amostra, o índice NLCDG apresentou valor negativo, sinalizando que as fontes de capital de giro foram superiores às aplicações de ca-

Figura 3: Longo prazo das cooperativas agropecuárias no período 1999 a 2004

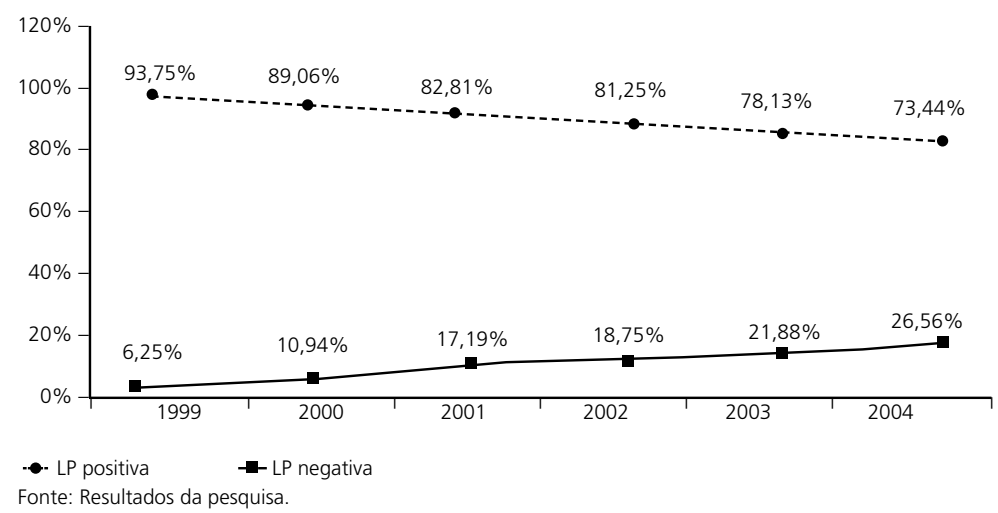

Figura 4: CDGP das cooperativas agropecuárias no período 1999 a 2004

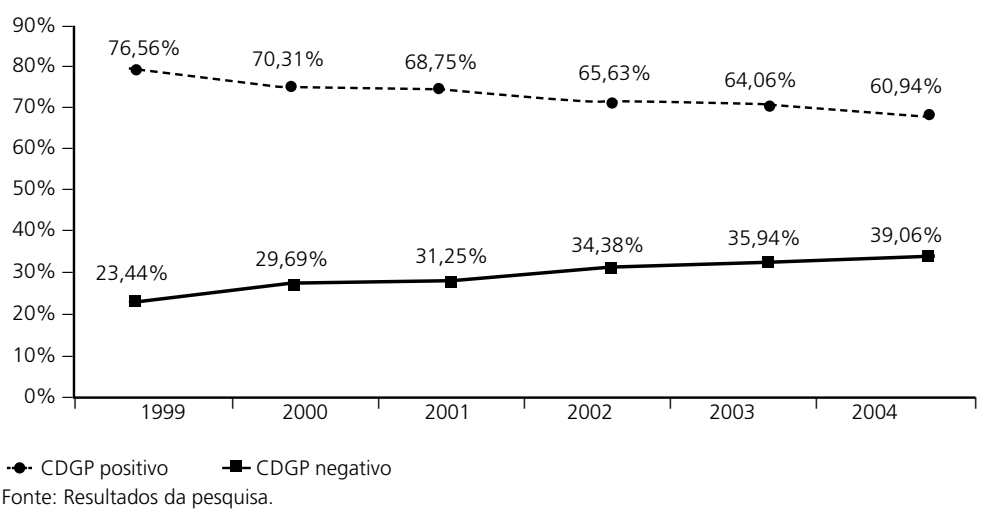


pital de giro. Nesse caso, as cooperativas utilizaram recursos operacionais para financiar seus investimentos em capital de giro e ainda geraram recursos para financiar outras aplicações, como, por exemplo, em ativos fixos.

Para 57 cooperativas, ou seja, 89,06\% da amostra, o índice Tesouraria-T apresentou valor negativo. Esse resultado indica que as cooperativas analisadas em sua maior parte utilizaram recursos financeiros de curto prazo para financiar suas necessidades líquidas de capital de giro. Em seis cooperativas, ou seja, 9,38\% da amostra, o índice Tesouraria-T apresentou valor positivo, e isso demonstra que essas cooperativas possuíam aplicações no curto prazo, caracterizando situação de folga financeira.

Em 47 cooperativas, ou seja, 73,44\% da amostra, o índice LP apresentou valor positivo. Isso significa que a maior parte das cooperativas possuía fontes de recursos de terceiros de longo prazo (exigível) financiando as suas atividades operacionais. Em 17 cooperativas, ou seja, 26,56\% da amostra, o índice LP apresentou valor negativo, sinalizando que para essas cooperativas existiam aplicações no realizável a longo prazo exigindo financiamento.

Para 25 cooperativas, ou seja, 39,06\% da amostra, o índice CDGP apresentou valor negativo, isto é, essas cooperativas não possuíam capital de giro próprio para financiar suas atividades operacionais. Para 39 cooperativas, ou seja, $60,94 \%$ da amostra, esse índice apresentou valor positivo, revelando a existência de capital de giro próprio no financiamento das operações.

Para melhor posicionar as cooperativas analisadas em relação ao índice Termômetro da Situação Financeira (TSF), optou-se pela construção de índices-padrões. Os dados levantados pela pesquisa foram organizados na tabela 3 , na qual se identificam os noves decis. O papel da mediana ( $5^{\circ}$ decil), ao dividir a série de dados em duas metades, é possibilitar a comparação de um elemento do universo com os demais, a fim de conhecer a sua posição relativa, na ordem de grandeza do universo. Entretanto, a mediana isoladamente é insuficiente para comparações precisas, daí a necessidade de calcu-

Tabela 3: Índice-padrão do Termômetro da Situação Financeira, TSF no ano 2004

\begin{tabular}{lccccccccc}
\hline Índice & $1^{\circ}$ decil & $2^{\circ}$ decil & $3^{\circ}$ decil & $4^{\circ}$ decil & $5^{\circ}$ decil & $6^{\circ}$ decil & $7^{\circ}$ decil & $8^{\circ}$ decil & $9^{\circ}$ decil \\
\hline TSF & $-86,34$ & $-75,80$ & $-70,68$ & $-66,57$ & $-60,70$ & $-50,72$ & $-36,32$ & $-21,17$ & 2,21 \\
\hline
\end{tabular}

Fonte: Resultados da pesquisa. 
larem-se os decis, que distribuem o universo em fatias, cada uma com 10\% dos elementos do universo (Matarazzo, 1998).

O cálculo dos índices-padrões do índice TSF revelou que 50\% das cooperativas financiaram suas necessidades líquidas de capital de giro com recursos de terceiros de curto prazo (tesouraria negativa), na proporção equivalente a pelo menos $60,70 \%$ das suas necessidades. Em $10 \%$ das cooperativas esse financiamento atingiu $86,34 \%$ das necessidades líquidas de capital de giro.

Pelas informações extraídas dos índices calculados, observa-se que o equilíbrio financeiro no financiamento das necessidades líquidas de capital de giro das cooperativas agropecuárias da amostra selecionada não foi alcançado. A maior parte das cooperativas não foi capaz de, preferencialmente, financiar suas necessidades líquidas de capital de giro com recursos próprios, ou seja, pelo autofinanciamento. Foram utilizadas em maior proporção fontes de recursos de terceiros de curto prazo, geralmente de maior custo e de menor prazo.

\section{CONSIDERAÇÕES FINAIS}

O referencial teórico exposto nos tópicos iniciais e a análise dos resultados amparados pela metodologia permitiram a reflexão sobre as conclusões da pesquisa no sentido de atender aos objetivos propostos, cujos pontos principais se relatam a seguir.

O novo cenário da economia mundial apresenta-se para as sociedades cooperativas sob a forma de uma permanente contradição: manter-se uma empresa competitiva, capaz de enfrentar multinacionais de grande porte que conquistam seus mercados, e, ao mesmo tempo, atender às necessidades dos seus associados, nem sempre em condições de fazê-lo com algum resultado.

Essa contradição impõe limites ao financiamento do seu processo de expansão com recursos próprios (autofinanciamento), especialmente em economias em desenvolvimento, em que o fator capital é geralmente escasso e caro, e sua necessidade aparentemente é infinita.

A economia brasileira apresenta uma enorme carência de capital, com expressiva demanda por investimentos produtivos e pouca oferta de crédito 
privado de longo prazo, tornando inexeqüíveis os investimentos de longa maturação.

No que tange à questão principal do estudo - o financiamento das necessidades líquidas de capital de giro das cooperativas agropecuárias paranaenses - , constatou-se um elevado índice de recursos de terceiros, principalmente os de curto prazo, em sua estrutura de capital.

O endividamento associado à baixa capacidade de cobertura dos encargos financeiros pelas sobras operacionais produziu nas cooperativas pesquisadas um grave desequilíbrio financeiro.

Se, por um lado, não há dúvida quanto à importância do cooperativismo agropecuário para o desenvolvimento econômico nacional, por outro, constata-se uma absoluta falta de orientação ao setor no que se refere às novas alternativas de capitalização e financiamento, destacando-se aqui: as experiências internacionais, como a captação de recursos pela emissão de títulos de dívida, as parcerias estratégicas com sociedades anônimas ou por meio das estruturas holding e até a abertura direta do seu capital pela emissão de ações preferenciais.

Como contribuição à futuras linhas de investigação, levantam-se as seguintes questões:

As cooperativas agropecuárias têm, no autofinanciamento, os recursos necessários para financiar um crescimento sustentável?

Essa forma de capitalização é capaz de definir uma estrutura de capital que garanta os desempenhos econômico e social da sociedade?

\section{REFERÊNCIAS BIBLIOGRÁFICAS}

ALVES, A. G. As cooperativas agropecuárias e o BRDE: histórico, situação atual e perspectivas. Banco Regional de Desenvolvimento do Extremo Sul, Diretoria de Planejamento, Superintendência de Planejamento, 92 p., 2003.

BASTIANI, I. C. R. Estrutura e custo de capital: um estudo sobre a realidade das cooperativas agropecuárias do Paraná. In: Encontro Brasileiro de Finanças, 1, 26 p., 2001. Rio de Janeiro. Sociedade Brasileira de Finanças. Anais eletrônicos. Disponível em: < http://www. sbfin.org.br>. Acesso em: 18 jan. 2005.

BENETTI, M. D. Endividamento e crise no cooperativismo empresarial do Rio Grande do Sul: análise do caso Fecotrigo/Centralsul, 1975-83. In: BENETTI, M. D.; FRANTZ, T. R. (Coord.). Desenvolvimento e crise do cooperativismo empresarial do Rio Grande do Sul, 1957-84. Porto Alegre: FEE, 1985. 
BIANCO, J.; CARDOSO, J. L.; FUCHIDA, M. A.; FREITAS, M. L. Revitalização do segmento cooperativista agropecuário - RECOOP. In: CONGRESSO BRASILEIRO DE ECONOMIA E SOCIOLOGIA GERAL, 36, v. 2. Anais. Poços de Caldas, 1998.

EW, A. R. Reestruturação do cooperativismo agropecuário no Rio Grande do Sul: os casos Cosuel e Coapel, anos 90. (Dissertação de Mestrado). Universidade Federal do Rio Grande do Sul, Porto Alegre, 2001.

FLEURIET, M.; KEHDY, R.; BLANC, G. A dinâmica financeira das empresas brasileiras. Belo Horizonte: Fundação Dom Cabral, 1980.

GIMENES, R. M. T. Análisis del comportamiento de los administradores financieros respecto al coste y estructura de capital. Aplicación a las cooperativas agropecuarias del Estado del Paraná. (Tese de Doutorado), Universidad de León: Espanha, 1999.

GONZALEZ, B.; COSTA, S. Agricultura brasileira: modernização e desempenho. Teoria e evidência econômica, v. 5, n. 10, 1998.

MARQUES, J. A. V. C.; BRAGA, R. Análise dinâmica do capital de giro: o modelo Fleuriet. Revista de Administração de Empresas, São Paulo, v. 35, n. 3, p. 49-63, 1995.

MATARAZZO, D. C. Análise financeira de balanços: abordagem básica e gerencial. 5. ed. São Paulo: Atlas, 1998. 471 p.

PEREIRA, A. C. Contribuição à análise e estruturação das demonstrações financeiras das sociedades cooperativas brasileiras: ensaio de abordagem social. (Tese de Doutorado em Contabilidade). Universidade de São Paulo, São Paulo, 1993.

SANTI FILHO, A.; OLINQUEVITCH, J. L. Análise de balanços para controle gerencial. 3. ed. São Paulo: Atlas, 1995.282 p.

SANTOS, E. Decisões financeiras em uma cooperativa agropecuária: uma análise pelo modelo Fleuriet. In: CONGRESSO DA SOCIEDADE BRASILEIRA DE ECONOMIA E SOCIOLOGIA RURAL, 43. Ribeirão Preto, Anais do XLIII Congresso da Sociedade Brasileira de Economia e Sociologia Rural. Fearp, v. 1. p. 38-58, 2005.

SILVA, J. P. Análise financeira das empresas. 3. ed. São Paulo: Atlas, 1995. 482 p.

SCHNEIDER, J. Democracia, participação e autonomia cooperativa. São Leopoldo: Unisinos, 1991.

UNIRCOOP - Rede de Universidades das Américas para Estudos Cooperativos e Associativos. Panorama do Cooperativismo Brasileiro: história, cenários e tendências. Recife: Unircoop, 2003. disponível em: <http: //www.neticoop.org.uy/article180.html>. Acesso em: 12 mar. 2006. 